OPEN ACCESS

Edited by:

Amer Hakki,

Gulf Organisation for Research \&

Development, Qatar

Reviewed by:

Cláudia Gomes Silva,

University of Porto, Portugal

Jonathan Zacharias Bloh,

DECHEMA Forschungsinstitut

(DFI), Germany

*Correspondence:

Shigeru Kohtani

kohtani@huhs.ac.jp

Hideto Miyabe

miyabe@huhs.ac.jp

Specialty section:

This article was submitted to

Catalysis and Photocatalysis,

a section of the journal

Frontiers in Chemistry

Received: 15 April 2019 Accepted: 02 September 2019 Published: 18 September 2019

Citation:

Kohtani S, Kawashima A and Miyabe H (2019) Stereoselective Organic Reactions in Heterogeneous

Semiconductor Photocatalysis.

Front. Chem. 7:630.

doi: 10.3389/fchem.2019.00630

\section{Stereoselective Organic Reactions in Heterogeneous Semiconductor Photocatalysis}

\author{
Shigeru Kohtani ${ }^{*}$, Akira Kawashima and Hideto Miyabe* \\ School of Pharmacy, Hyogo University of Health Sciences, Kobe, Japan
}

The most significant feature of heterogeneous semiconductor photocatalysis is that both oxidation and reduction occur in a one-pot process. Thus, photocatalysis leads to unique redox organic reactions that cannot be achieved by conventional techniques using oxidants or reductants. Semiconductor photocatalysis is expected to be a new method for fine chemical syntheses of highly valuable molecules such as chiral medicines. However, the use of semiconductor photocatalysts in stereoselective reactions has been limited so far. This mini-review highlights recent progress in stereoselective organic reactions using semiconductor photocatalysts, briefly summarizing the enantio- and diastereoselective reactions based on the currently available literature.

Keywords: enantioselective reactions, diastereoselective reactions, semiconductor photocatalysis, heterogeneous photocatalysis, titanium dioxide, chiral reagents

\section{INTRODUCTION}

Chirality is a fundamentally important topic in science because biologically active species such as enzymes selectively recognize a single enantiomer. Therefore, asymmetric synthesis has attracted extensive attention not only in organic chemistry but also in the medicinal, pharmaceutical and agricultural sciences. Up to now, highly stereoselective synthesis of chiral compounds has been made on a plant scale by conventional stereo-controlling methods (Crawley and Trost, 2012).

Heterogeneous photocatalysis on semiconductors is a unique redox methodology compared to traditional techniques using oxidants or reductants. Such photocatalysis, especially using titanium dioxide $\left(\mathrm{TiO}_{2}\right)$, has attracted much attention in many fields (Fujishima et al., 2000). Despite significant advances, little attention has been focused on the use of semiconductors for synthetic organic chemistry (Fox, 1987; Fagnoni et al., 2007; Shiraishi and Hirai, 2008; Kohtani and Miyabe, 2014; Lang et al., 2014a,b; Kisch, 2017; Kou et al., 2017; Ma et al., 2018). Semiconductor photocatalysis has several great advantages (Kohtani et al., 2012): (1) It leads to unique one-pot redox transformations. (2) Particular reductants or oxidants are not necessary. (3) It avoids the use of dangerous and harmful reagents. (4) It proceeds under mild conditions (normal temperature and pressure). (5) Semiconductors such as $\mathrm{TiO}_{2}$ are chemically stable, easily separable, and reusable. Thus, such photocatalysis shows great promise to become "green" chemical processes. Moreover, semiconductor photocatalysis is expected to grow as a new synthetic method for preparing highly valuable molecules such as chiral medicines.

Enantioselective synthesis using homogeneous photocatalysts such as chiral metal complexes has attracted wide attention in recent years (Amador and Yoon, 2016; Megan et al., 2016). However, the use of semiconductors in asymmetric synthesis has been limited so far. To our knowledge, $\sim 10$ reports have been published on successful examples of enantio- and 
diastereoselective reactions using semiconductor photocatalysts. This mini-review highlights the progress in stereoselective chemical transformations on photoirradiated surfaces of semiconductor particles, briefly summarizing representative examples of enantio- and diastereoselective reactions based on the currently available literature.

\section{ENANTIOSELECTIVE REACTIONS}

In 1990, Wang et al. (1990) reported that the enantioselective photoreduction of 3-methyl-2-oxobutanoic acid 1 proceeded in aqueous methanol suspension containing platinum loaded $\mathrm{TiO}_{2}\left(\mathrm{Pt} / \mathrm{TiO}_{2}\right)$ and chiral 2,2'-bis(diphenylphosphino)1,1'-binaphthyl (BINAP)-Rh complex to give 2-hydroxy-3methylbutanoic acid 2 in $75 \%$ yield and $60 \%$ ee (Figure 1A). The mechanism involved in this asymmetric induction is still unclear. In this transformation, the photo-generated conduction band $(\mathrm{CB})$ electrons must migrate toward $\mathrm{Pt}$ on $\mathrm{TiO}_{2}$. A route involving the transfer of electrons accumulated on Pt to the chiral BINAP-Rh complex and the subsequent reduction of $\mathbf{1}$ by the BINAP-Rh anion is proposed as a possible mechanism. Chiral metal catalysts possessing BINAP ligands are known to be efficient catalysts for the enantioselective hydrogenation of various olefinic and ketonic substrates in the presence of gaseous hydrogen $\left(\mathrm{H}_{2}\right)$ in the dark (Shimizu et al., 2007). Accumulated electrons on $\mathrm{Pt}$ will reduce protons $\left(\mathrm{H}^{+}\right)$to produce $\mathrm{H}_{2}$. Therefore, it is possible that substrate $\mathbf{1}$ is reduced by gaseous $\mathrm{H}_{2}$ and the chiral BINAP-Rh complex as an alternate mechanism.

Kohtani et al. (2018) reported the novel surface-selective and enantioselective hydrogenation of aromatic ketones 3 induced by chiral $\alpha$-hydroxy acids-coadsorbed on $\mathrm{TiO}_{2}$. When $(R)$ mandelic acid was used as the chiral reagent, the $S$-enantiomers of secondary alcohols 4 were predominantly obtained with reasonable enantioselectivities (ca. $40 \%$ ee) (Figure 1B). The enantioselectivities were strongly affected by the chiral reagents. Chiral mandelic acids having hydroxyl, phenyl and carboxy groups at the chiral carbon atom showed the best enantioselective stereocontrol. Interestingly, P25 (anatase/rutile $=\mathrm{ca} .9 / 1$ ) and an anatase $\mathrm{TiO}_{2}$ sample (JRC-TIO-13) exhibited relatively high enantioselectivities, whereas another anatase $\mathrm{TiO}_{2}$ (JRC-TIO-7) and the rutile $\mathrm{TiO}_{2}$ led to low $\%$ ee. Thus, the enantioselectivity was affected by the $\mathrm{TiO}_{2}$ crystalline samples. The reduction of ketones 3 on $\mathrm{TiO}_{2}$ proceeds via electron transfer to 3 leading to a ketyl radical species and further electron transfer to form an anion (Kohtani et al., 2014). Asymmetric induction is achieved through stereoselective protonation of the anion species by $(R)$ mandelic acid co-adsorbed on the $\mathrm{TiO}_{2}$ surface.

Jang's group reported $\mathrm{TiO}_{2}$-induced enantioselective $\alpha$ oxyamination of aldehyde 5 with 2,2,6,6-tetramethylpiperidine$N$-oxyl (TEMPO) by the use of a chiral amine catalyst (Figure 1C) (Ho et al., 2011). This reaction proceeds via a chiral enamine intermediate, generated from aldehyde $\mathbf{5}$ and MacMillan's catalyst, to give oxyamination product $\mathbf{6}$ in $60 \%$ yield with $63 \%$ ee. Two pathways are proposed for the oxidative transformation of the enamine to the iminium cation intermediate. The first pathway involves the oxidation of the enamine to a cation radical followed by stereoselective trapping of the cation radical by TEMPO (path $a$ in Figure 1C). The second pathway involves the stereoselective reaction of the enamine with a cation species $\left(\mathrm{TEMPO}^{+}\right.$) generated by the oxidation of TEMPO (path $b$ in Figure 1C). The successful application to a tandem Michael addition-oxyamination was reported using N719 dye-sensitized $\mathrm{TiO}_{2}$ photocatalyst under visible light irradiation (Yoon et al., 2012).

Cherevatskaya et al. (2012) reported visible-light promoted enantioselective alkylation of aldehydes 7 by the use of several semiconductors and MacMillan's catalyst (Figure 1D). Later, Riente et al. (2014) achieved highly enantioselective $\alpha$-alkylation of 7 using bismuth-based semiconductor materials $\left(\mathrm{Bi}_{2} \mathrm{O}_{3}\right.$ and $\mathrm{Bi}_{2} \mathrm{~S}_{3}$ ) possessing a small band gap and MacMillan's catalyst under sunlight (Figure 1D). Li et al. (2015) studied enantioselective alkylation of aldehydes using a nanocomposite material of $\mathrm{PbBiO}_{2} \mathrm{Br}$ nanoparticles with a $\mathrm{NbSe}_{2}$ nanosheet. The key step in these reactions is presumed to be the stereoselective addition of alkyl radicals to the chiral enamine intermediates.

Shi et al. (2014) developed an enantioselective molecular imprinting technique for photoelectrochemical and photocatalytic recognition of enantiomers. They reported the chiral recognition and enantioselective decomposition of amino acids on chiral molecular-imprinted $\mathrm{ZnO}$ and anatase $\mathrm{TiO}_{2}$ crystallites. Interestingly, the use of anatase $\mathrm{TiO}_{2}$ crystallites with specifically exposed (001) facets led to higher enantioselective recognition, presumably caused by abundant surface hydroxyls on the (001) facet (Shi et al., 2014).

\section{DIASTEREOSELECTIVE REACTIONS AND ASYMMETRIC SYNTHESIS}

Marinković and Hoffmann reported the radical addition of tertiary amines to $\alpha, \beta$-unsaturated lactones using semiconductor photocatalyst powders of $\mathrm{TiO}_{2}$ and $\mathrm{ZnS}$ (Marinković and Hoffmann, 2001, 2003). They further developed the diastereoselective radical tandem addition-cyclization reaction of $(5 R)$-menthyloxyfuran-2(5H)-one 9 with aromatic tertiary amines using $\mathrm{TiO}_{2}$ or $\mathrm{ZnS}$ (Figure 2A) (Marinković and Hoffmann, 2004). Two stereoisomeric tetrahydroquinoline derivatives $\mathbf{1 0}$ and $\mathbf{1 1}$ were obtained with reasonable diastereoselectivities. The key radical was initially generated via the single electron oxidation of $N, N$-dimethylaniline. The stereoselective addition of the alkyl radical to lactone $\mathbf{9}$ followed by intramolecular radical trapping on the aromatic ring led to the cyclized adduct $\mathbf{1 0}$ as the major product.

Ohtani et al. (1990, 2001) reported the deaminocyclization of chiral L-lysine derivatives 12a-c and 2,6-diaminopimelic acids (DAP) 14a and 14b to piperidine derivatives 13 and 15, respectively (Figure 2B). In the presence of $\mathrm{PtO}_{2} / \mathrm{TiO}_{2}$, the deaminocyclization of L-lysine $\mathbf{1 2}$ a gave the piperidine2-carboxylic acid $\mathbf{1 3}$ in moderate enantioselectivity, probably due to the competitive oxidation of the two amino groups of 12a. Excellent enantioselectivities were achieved by protection of the $\alpha$-amino group. When the protected L-lysine derivatives 12b and 12c were employed, piperidine-2-carboxylic acid 13 

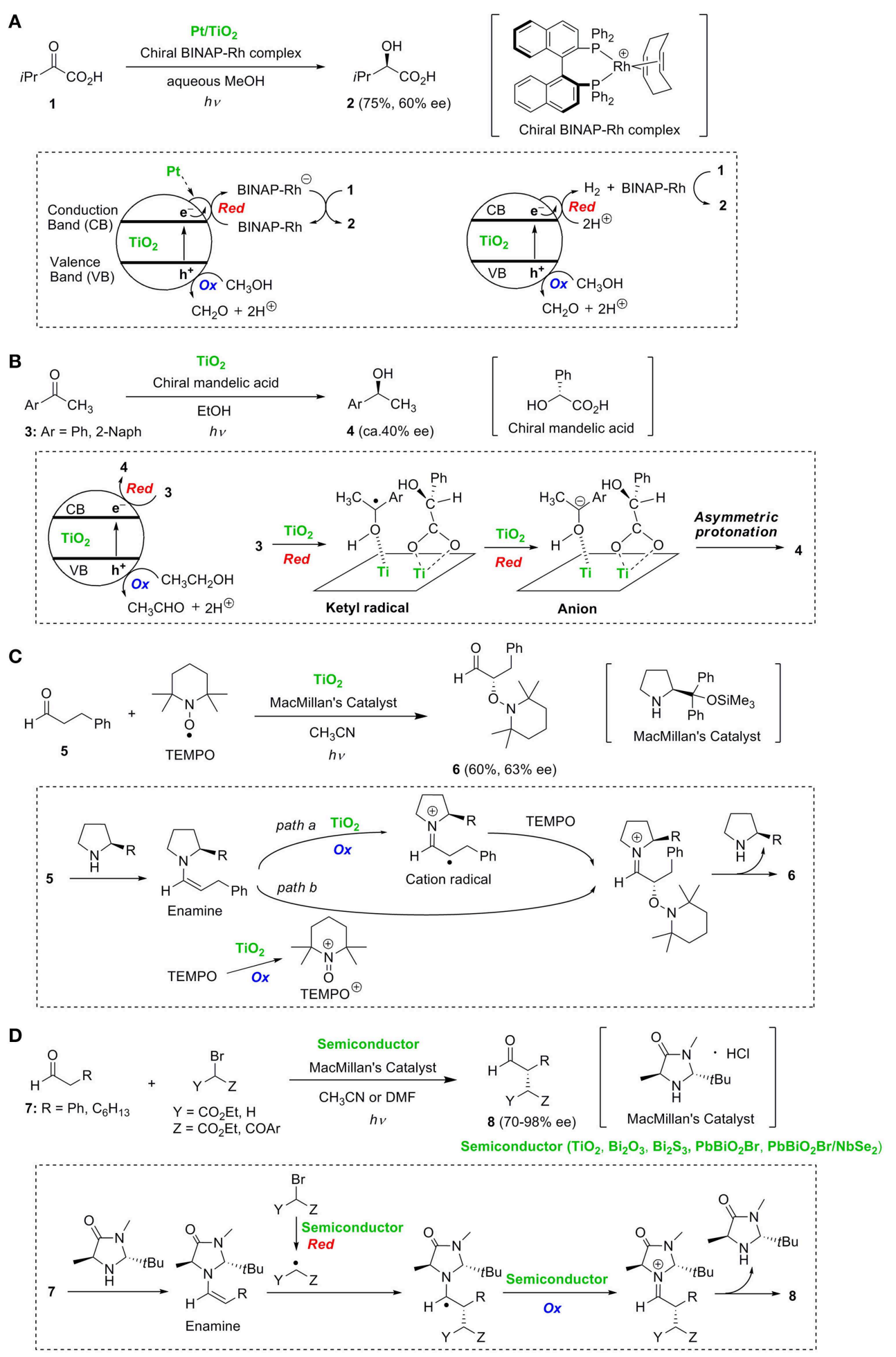

FIGURE 1 | Enantioselective reactions: (A) hydrogenation of $\alpha$-keto acid 1, (B) hydrogenation of aromatic ketones 3, (C) $\alpha$-oxyamination of aldehyde $\mathbf{5}$, and (D) $\alpha$-alkylation of aldehydes 7 .

was synthesized in 92 and $96 \%$ ee, respectively. Additionally, by deaminocyclization of a 1:1 mixture of racemic DAP $\mathbf{1 4 a}$ and meso DAP 14b, preferential production of trans-PDC 15 to cis-PDC 15 was achieved by changing the catalyst from $\mathrm{CdS}$ to $\mathrm{PtO}_{2} / \mathrm{CdS}$ (Figure 2B). The diastereoselectivity was determined at the final photocatalytic hydrogenation of the 
A<smiles>CC1CCC(O[C@H]2C=CC(=O)O2)CC(C)C1</smiles>

9<smiles>CN(C)c1ccccc1</smiles>

Semiconductor $\left(\mathrm{TiO}_{2}, \mathrm{ZnS}\right)$

$\mathrm{CH}_{3} \mathrm{CN}$

$h v$

$N, N$-Dimethylaniline<smiles>CN1C[C@@H]2[C@@H](O)OC(=O)[C@H]2c2ccccc21</smiles>

10 (major)

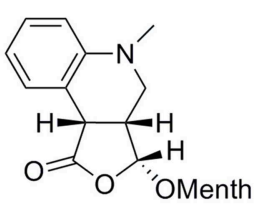

11 (minor)

Conversion $96 \%, 62 \%$ de (using $\mathrm{TiO}_{2}$ )

Conversion 92\%, 68\% de (using $\mathrm{ZnS}$ )

\section{$N, N$-Dimethylaniline}
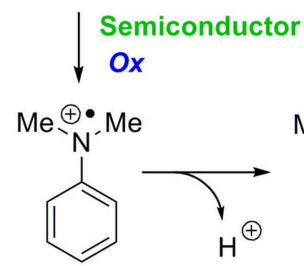<smiles>[CH]N(C)C</smiles><smiles>CNc1ccccc1</smiles><smiles>CC1CC(C)C(C)C(O[C@H]2OC(=O)C[C@H]2C)C1</smiles><smiles>CC(C)(C)C1(C)CCCCC1</smiles>

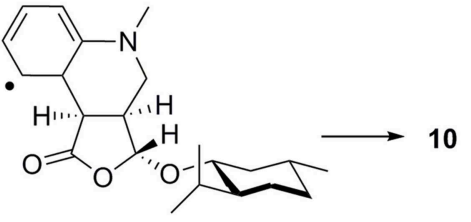

Radical

B
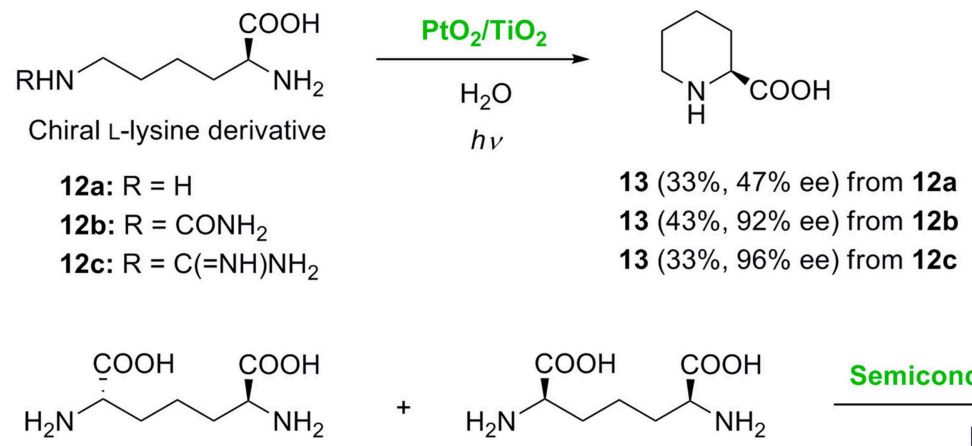

14a: racemic DAP (ca. 50\%)

14b: meso DAP (ca. 50\%)

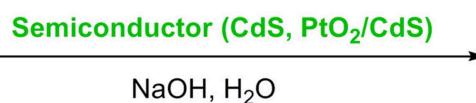

$h v$

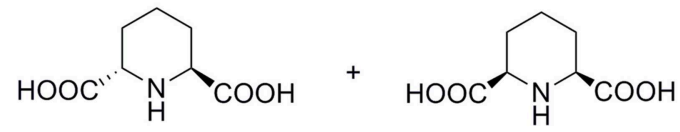

trans-15: trans-PDC cis-15: cis-PDC

$39 \%$, trans-15/cis-15 = 4.1 (using CdS) $33 \%$, trans-15/cis-15 = 0.3 (using $\mathrm{PtO}_{2} / \mathrm{CdS}$ )

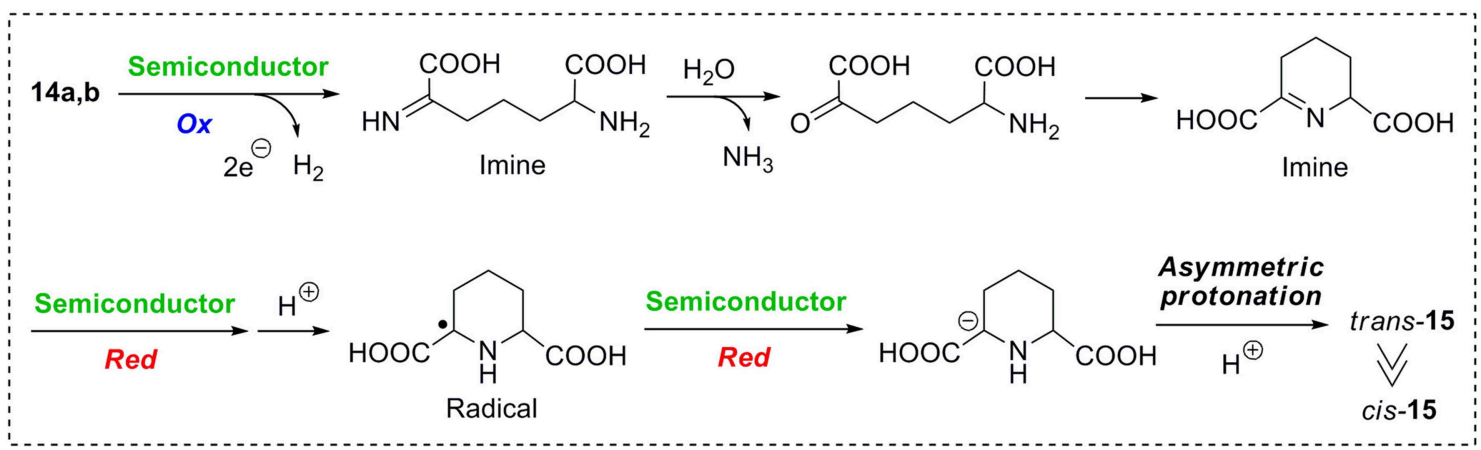

FIGURE 2 | (A) Diastereoselective tandem radical addition-cyclization reaction and (B) asymmetric synthesis of piperidine-2-carboxylic acid and diastereoselective cyclization. 
cyclic imine intermediate formed by oxidative deamination and cyclization. cis-15 would be obtained when the hydrogenation proceeds via syn-addition of hydrogen atoms to the $\mathrm{C}=\mathrm{N}$ bond of the cyclic imine. In contrast, trans-15 is selectively produced when reduction takes place via stepwise electron transfer and subsequent stereoselective protonation as illustrated in Figure 2B. Consequently, the opposite diastereoselective preparation of trans-PDC and cis-PDC was achieved by simply changing the catalyst.

\section{PHOTOBIOCATALYSIS FOR ASYMMETRIC SYNTHESIS}

Photobiocatalysis employing isolated enzymes or lysates involves three types of electron relay systems (Gulder and Seel, 2019): (1) photosensitizers (metal complexes or semiconductors, etc.), (2) reaction sites (enzymes), and (3) electron mediators such as methylviologen, nicotinamide adenine dinucleotide (phosphate) $\left(\mathrm{NAD}(\mathrm{P})^{+} / \mathrm{NAD}(\mathrm{P}) \mathrm{H}\right)$, and flavin mononucleotide $\left(\mathrm{FMN} / \mathrm{FMNH}_{2}\right)$. Excited electrons generated at the photosensitizer are relayed to the reaction site via the electron mediators. In addition, sacrificial electron donors (e.g., tertiary amines or water) are required to prevent oxidative self-degradation of the photosensitizers. Successful examples of highly enantioselective reactions using semiconductor photocatalysts have been reported. The asymmetric reduction of alkenes using old yellow enzymes in cooperation with CdSe quantum dots (Burai et al., 2012), gold nanoparticle- loaded $\mathrm{TiO}_{2}\left(\mathrm{Au} / \mathrm{TiO}_{2}\right)$, or vanadium doped $\mathrm{TiO}_{2}$ (Mifsud et al., 2014) has been investigated. Moreover, stereoselective activation of C$\mathrm{H}$ bonds during peroxygenase-catalyzed hydroxylation of

\section{REFERENCES}

Amador, A. G., and Yoon, T. P. (2016). A chiral metal photocatalyst architecture for highly enantioselective photoreactions. Angew. Chem. Int. Ed. 55, 2304-2306. doi: 10.1002/anie.201511443

Burai, T. N., Panay, A. J., Zhu, H., Lian, T., and Lutz, S. (2012). Lightdriven quantum dot-mediated regeneration of FMN to drive reduction of ketoisophorone by old yellow enzyme. ACS Catal. 2, 667-670. doi: $10.1021 / \mathrm{cs} 300085 \mathrm{~h}$

Cherevatskaya, M., Neumann, M., Füldner, S., Harlander, C., Kümmel, S., Dankesreiter, S., et al. (2012). Visible-light-promoted stereoselective alkylation by combining heterogeneous photocatalysis with organocatalysis. Angew. Chem Int. Ed. 51, 4062-4066. doi: 10.1002/anie.201108721

Crawley, M. L., and Trost, B. M. (2012). Applications of Transition Metal Catalysis in Drug Discovery and Development: An Industrial Perspective. Hoboken, NJ: John Wiley \& Sons, Inc.

Fagnoni, M., Dondi, D., Ravelli, D., and Albini, A. (2007). Photocatalysis for the formation of the C-C bond. Chem. Rev. 106, 2725-2756. doi: $10.1021 / \operatorname{cr} 068352 \mathrm{x}$

Fox, M. A. (1987). Selective formation of organic compounds by photoelectrosynthesis at semiconductor particles. Top. Curr. Chem. 142, 71-99.

Fujishima, A., Rao, T. N., and Tryk, D. A. (2000). Tianium dioxide photocatalysis. J. Photochem. Photobiol. C Photochem. Rev. 1, 1-21. doi: 10.1016/S1389-5567(00)00002-2

Gulder, T., and Seel, C. J. (2019). Biocatalysis fueled by light: on the versatile combination of photocatalysis and enzymes. ChemBioChem 20, 1871-1897. doi: $10.1002 /$ cbic. 201800806 alkylbenzenes and alkanes has been achieved using $\mathrm{Au} / \mathrm{TiO}_{2}$ (Zhang et al., 2017, 2018).

\section{CONCLUSION AND OUTLOOK}

This mini-review focuses on the enantio- and diastereoselective organic reactions occurring in several semiconductor photocatalyses. As mentioned in this review, our group found that enantioselective hydrogenation on $\mathrm{TiO}_{2}$ was strongly affected by the surface structure of $\mathrm{TiO}_{2}$ (Kohtani et al., 2018). Recently, it was also demonstrated that adsorption of chiral molecules on a specific semiconductor nanoparticle surface (mercury sulfide: HgS) was associated with the growth of chiral semiconductor nanoparticles (Kuno et al., 2018). Thus, one promising strategy may be the use of highly uniform semiconductor nanocrystals with specific exposure of the reactive facets. If these facets could be selectively covered with stable chiral compounds, enantioselective reactions would be greatly enhanced. Therefore, increasing attention should be given to the development of specifically reactive facets on semiconductor materials for stereoselective organic transformations.

\section{AUTHOR CONTRIBUTIONS}

All authors listed have made a substantial, direct and intellectual contribution to the work, and approved it for publication.

\section{FUNDING}

This work was supported in part by JSPS KAKENHI Grant-inAid for Scientific Research (C) Grant Numbers 16K08188 (to $\mathrm{HM}$ ) and 19K05681 (to SK).

Ho, X.-H., Kang, M.-J., Kim, S.-J., Park, E., and Jang, H.-Y. (2011). Green organophotocatalysis. $\mathrm{TiO}_{2}$-induced enantioselective $\alpha$-oxyamination of aldehydes. Catal. Sci. Tech. 6, 923-926. doi: 10.1039/c1cy00183c

Kisch, H. (2017). Semiconductor photocatalysis for chemoselective radical coupling reactions. Acc. Chem. Res. 50, 1002-1010. doi: 10.1021/acs.accounts.7b00023

Kohtani, S., Kamoi, Y., Yoshioka, E., and Miyabe, H. (2014). Kinetic study on photocatalytic hydrogenation of acetophenone derivatives on titanium dioxide. Catal. Sci. Tech. 4, 1084-1091. doi: 10.1039/c3cy00879g

Kohtani, S., Kawashima, A., Masuda, F., Sumi, M., Kitagawa, Y., Yoshioka, E., et al. (2018). Chiral $\alpha$-hydroxy acid-coadsorbed $\mathrm{TiO}_{2}$ photocatalysts for asymmetric induction in hydrogenation of aromatic ketones. Chem. Commun. 54, 12610-12613. doi: 10.1039/c8cc07295g

Kohtani, S., and Miyabe, H. (2014). "Titanium dioxide-induced photocatalytic reduction for organic synthesis" in Titanium Dioxide: Chemical Properties, Applications and Environmental Effects, ed J. Brown (New York, NY: Nova Science Publishers Inc.), 157-176.

Kohtani, S., Yoshioka, E., and Miyabe, H. (2012). "Photocatalytic hydrogenation on semiconductor particles" in Hydrogenation, eds I. Karamé and C. Rijeka (Oxford: Intech), 291-308. doi: 10.5772/45732

Kou, J., Lu, C., Wang, J., Chen, Y., Xu, Z., and Varma, R. S. (2017). Selectivity enhancement in heterogeneous photocatalytic transformations. Chem. Rev. 117, 1445-1514. doi: 10.1021/acs.chemrev.6b00396

Kuno, J., Imamura, Y., Katouda, M., Tashiro, M., Kawai, T., and Nakashima, T. (2018). Inversion of optical activity in the synthesis of mercury sulfide nanoparticles: role of ligand coordination. Angew. Chem. Int. Ed. 57, 12022-12026. doi: 10.1002/anie.201807191 
Lang, X., Chen, X., and Zhao, J. (2014a). Heterogeneous visible light photocatalysis for selective organic transformations. Chem. Soc. Rev. 43, 473-486. doi: 10.1039/c3cs60188a

Lang, X., Ma, W., Chen, C., Ji, H., and Zhao, J. (2014b). Selective aerobic oxidation mediated by $\mathrm{TiO}_{2}$ photocatalysis. Acc. Chem. Res. 47, 355-363. doi: 10.1021/ar4001108

Li, X., Wang, J., Xu, D., Sun, Z., Zhao, Q., Peng, W., et al. (2015). NbSe 2 nanosheet supported $\mathrm{PbBiO}_{2} \mathrm{Br}$ as a high performance photocatalyst for the visible lightdriven asymmetric alkylation of aldehyde. ACS Sustainable Chem. Eng. 3, 1017-1022. doi: 10.1021/acssuschemeng.5b00182

Ma, D., Liu, A., Li, S., Lu, C., and Chen, C. (2018). $\mathrm{TiO}_{2}$ photocatalysis for C-C bond formation. Catal. Sci. Tech. 8, 2030-2045. doi: 10.1039/C7CY01458A

Marinković, S., and Hoffmann, N. (2001). Efficient radical addition of tertiary amines to electron-deficient alkenes using semiconductors as photochemical sensitisers. Chem. Commun. 1576-1578. doi: 10.1039/b104387k

Marinković, S., and Hoffmann, N. (2003). Semiconductors as sensitisers for the radical addition of tertiary amines to electron deficient alkenes. Int. J. Photoenergy 5, 175-182. doi: 10.1155/S1110662X03000308

Marinković, S., and Hoffmann, N. (2004). Diastereoselective radical tandem addition-cyclization reactions of aromatic tertiary amines by semiconductorsensitized photochemical electron transfer. Eur. J. Org. Chem. 2004, 3102-3107. doi: 10.1002/ejoc.200400102

Megan, H. S., Twilton, J., and MacMillan, D. W. C. (2016). Photoredox catalysis in organic chemistry. J. Org. Chem. 81, 6898-6926. doi: 10.1021/acs.joc.6b01449

Mifsud, M., Gargiulo, S., Iborra, S., Arends, I. W. C. E., Hollmann, F., and Corma, A. (2014). Photobiocatalytic chemistry of oxidoreductases using water as the electron donor. Nat. Commun. 5, 3145-3150. doi: 10.1038/ncomms4145

Ohtani, B., Kusakabe, S., Okada, K., Tsuru, S., Nishimoto, S., Amino, Y., et al. (2001). Photocatalytic stereoselective N-cyclization of 2,6-diaminopimelic acid into piperidine-2,6-dicarboxylic acid by an aqueous suspension of activated cadmium(II) sulfide particles. J. Chem. Soc. Perkin Trans. 2, 201-209. doi: 10.1039/b0069671

Ohtani, B., Tsuru, S., Nishimoto, S., and Kagiya, T. (1990). Photocatalytic one-step syntheses of cyclic imino acids by aqueous semiconductor suspensions. J. Org. Chem. 55, 5551-5553. doi: 10.1021/jo00308a005

Riente, P., Matas Adams, A., Albero, J., Palomares, E., and Pericàs, M. A. (2014). Light-driven organocatalysis using inexpensive, nontoxic $\mathrm{Bi}_{2} \mathrm{O}_{3}$ as the photocatalyst. Angew. Chem. Int. Ed. 53, 9613-9616. doi: 10.1002/anie.201405118
Shi, H., Chen, C., Tang, B., and Zhao, G. (2014). Photoelectrochemical enantioselective recognition of amino acid enantiomers on (001) facet $\mathrm{TiO}_{2}$ surface. Electrochim. Acta 146, 359-364. doi: 10.1016/j.electacta2014. 08.135

Shimizu, H., Nagasaki, I., Matsumura, K., Sayo, N., and Saito, T. (2007). Developments in asymmetric hydrogenation from an industrial perspective. Acc. Chem. Res. 40, 1385-1393. doi: 10.1021/ar70 0101x

Shiraishi, Y., and Hirai, T. (2008). Selective organic transformations on titanium oxide-based photocatalysts. J. Photochem. Photobiol. C Photochem. Rev. 1, 1-21. doi: 10.1016/j.jphotochemrev.2008.05.001

Wang, H., Sakata, T., Azuma, M., Ohta, T., and Takaya, H. (1990). Photocatalytic asymmetric reduction of 3-methyl-2-oxobutanoic acid with chiral $\mathrm{Rh}(\mathrm{I})$ complexes and powdery semiconductors. Chem. Lett. 19, 1331-1334. doi: 10.1246/cl.1990.1331

Yoon, H.-S., Ho, X.-H., Jang, J., Lee, H.-J., Kim, S.-J., and Jang, H.-Y. (2012). N719 dye-sensitized organophotocatalysis: enantioselective tandem michael addition/oxyamination of aldehydes. Org. Lett. 14, 3272-3275. doi: 10.1021/ol3011858

Zhang, W., Burek, B. O., Fernández-Fueyo, E., Alcalde, M., Bloh, J. Z., and Hollmann, F. (2017). Selective activation of C-H bonds in a cascade process combining photochemistry and biocatalysis. Angew. Chem. Int. Ed. 56, 15451-15455. doi: 10.1002/anie.201708668

Zhang, W., Fernández-Fueyo, E., Ni, Y., Schie, M., Gacs, J., Renirie, R., et al. (2018). Selective aerobic oxidation reactions using a combination of photocatalytic water oxidation and enzymatic oxyfunctionalisations. Nat Catal. 1, 55-62. doi: 10.1038/s41929-017-0001-5

Conflict of Interest Statement: The authors declare that the research was conducted in the absence of any commercial or financial relationships that could be construed as a potential conflict of interest.

Copyright (c) 2019 Kohtani, Kawashima and Miyabe. This is an open-access article distributed under the terms of the Creative Commons Attribution License (CC BY). The use, distribution or reproduction in other forums is permitted, provided the original author(s) and the copyright owner(s) are credited and that the original publication in this journal is cited, in accordance with accepted academic practice. No use, distribution or reproduction is permitted which does not comply with these terms. 